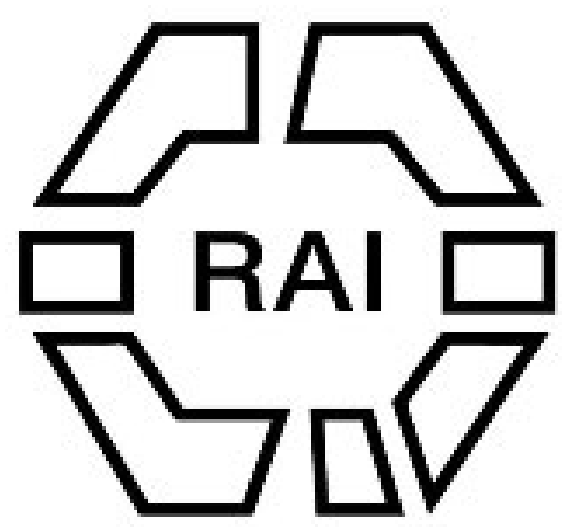

Upon a Scaphoid Skull. A Letter from Prof. Luigi Calori to Dr. Barnard Davis Author(s): Luigi Calori and J. Barnard Davis

Source: The Journal of the Anthropological Institute of Great Britain and Ireland, Vol. 2 (1873), pp. 140-150

Published by: Royal Anthropological Institute of Great Britain and Ireland

Stable URL: http://www.jstor.org/stable/2841156

Accessed: 14/06/2014 23:59

Your use of the JSTOR archive indicates your acceptance of the Terms \& Conditions of Use, available at http://www.jstor.org/page/info/about/policies/terms.jsp

JSTOR is a not-for-profit service that helps scholars, researchers, and students discover, use, and build upon a wide range of content in a trusted digital archive. We use information technology and tools to increase productivity and facilitate new forms of scholarship. For more information about JSTOR, please contact support@jstor.org. 


\section{Upon a Scaphoid Skull. A LetTer from Prof. Luigi Calori to Dr. Barnard Davis.*}

IN the first number of this Journal, a comprehensive notice was given of the anatomical essays of Professor Calori, which bear so intimate a relation to Anthropology. No less than four of his treatises were embraced, all exhibiting the hand of a master in the science to which he is devoted. At that time it was little thought that another would make its appearance before the notice was printed.

This "Letter" from the Professor of Anatomy at Bologna, is of the highest importance upon the subject to which it refers. The scaphoid skull described and delineated in it, is that of the boy Antonio, whose brain has been already treated upon in our author's late anatomical memoir upon "The Brain in the two Italian Brachycephalic and Dolichocephalic Types." Some account of this very valuable treatise was given in No. I. of the "Journal of the Anthropological Institute," p. 115, where there appeared the brief history of "Antonio," to whom this cranium appertained. Dr. Calori included his brain among those of dolichocephalous Italians, as an exemplification of the extreme development of this organ in the antero-posterior direction. The present letter refers to the skull, which was developed upon the brain.

Professor Calori designates the cranium a "scaphoid" skull, rather than scaphocephalic, after Von Baer, in order to avoid an appearance of repetition; and there is no doubt that the designation is more correct. Its subject was a boy of fourteen years of age. Antonio was born at Biegne, in the province of Como, of humble parents, with his head formed thus at birth. There was no difficulty in his birth. None of his relations presented any indications of scaphocephalism. He exhibited no defect in walking or speaking; was lively and healthy as he grew to the age of fourteen; had medium stature and some grace in his limbs; was always at work, continually doing something; he was domestic, amiable, disposed to good ways, of an acute understanding, of ready and prudent discourse, although his education was almost nothing ; he received instruction speedily, and, moreover, undertook to do things which he had not before seen done-for instance, to descend the organ, which he sounded when it appeared to him to be out of tune, trying it again and

* "Sopra un Cranio Scafoideo (Scaphocephalus Baerii)." Lettera del Prof. Cav. Luigi Calori, all' Illustre Craniologo Dott. J. Bernardo Davis, Vice-Presidente della Societá Anthropologica di Londra. Bologna, 1871. Quarto, con 5 Tavole. 
again, to mend it, attune it, and put it into order again, without any one having shown him or taught him the method. Besides which, he was very far from being like those youths who, in the exercise of the art to which they are devoted, when corrected and recorrected, fall at length into the same error; but in his case he immediately drew the rule, so as not to err. No one set him aside on account of the deformity of his head, or because it might be regarded as retributory ; thus he was received by all, and liked. One object Dr. Calori had in view in this recital was to compare the history of this scaphocephalic youth, Antonio, with that singular one of the Pomeranian weaver of Stettin, who died at the age of thirty-eight years.* This man exhibited the most exaggerated instance of scaphocephalism ever recorded, and, moreover, was known and observed by one who recounted this history almost all his life, so that there is no difficulty in comparing the one with the other. Dr. Brauıiiller knew the Pomeranian weaver from his childhood. From what has been stated, it clearly appears that both these scaphocephali manifested a quick understanding. They had no deficiency of mental power. Professor Calori's examination of the brain of Antonio, in his former treatise, illustrated by five beautiful plates, proved that it was large, complicated, and heavy. $\dagger$

The scaphoid cranium of Antonio is rather large, asymmetrical, and not furnished with bold lines and processes, but feeble, like the skulls of children of the same age, and generally of girls. It also calls to mind in its whole some of the features in the crania of embryos, of foetuses of tender age. The weight of the skull, including the lower jaw, amounts to five hundred grammes, i.e., nearly eighteen ounces.

Dr. Calori gives four excellent views of the cranium of the Biegnese Antonio, all of the size of nature-a profile or side view, a vertical view, a front view, and a back view. The norma verticalis exhibits an irregular ovoid, very long and narrow, with a wide anterior extremity. Neither the zygomatic arches nor the nasal bones project from the contours so as to be seen. These peculiarities distinguish this skull from that described and delineated by Von Baer,+, whilst in these respects it agrees

* This curions history was given by Dr. Braumüller, and is recorded in the memoir "On Synostotic Crania among Aboriginal Races of Men", by Joseph Barnard Davis, M.D., Haarlem, 1865, p. 35. It contains three plates of the natural size of this unique cranium.

+ “ "Del Cervello noi due Tipi Brachicefalo e Dolicocefalo Italiani.” 1870. Folio.

I “Die Makrokephalen im Boden der Krym und Österreichs." 1860. 4to. Tafel iii, figs. 1, 2, 3. 'I'hese small figures represent the Danish skull in the Blumenbachian Museum at Gottingen. 
with the cranium of the Pomeranian weaver.* The scaphoid crania, which have been represented vertically as well as in profile, are all remarkable for the great length and narrowness of the parietal region, and for its configuration; so also is that of Antonio.

Calori measured one half of the parietal region longitudinally in the middle in the curved line; the length amounted to a hundred and fifty-four millimetres. The same curved line measured transversely in the middle was only one hundred millimetres. This gives the breadth proportionately as 65 , which is a very small index, and proves the excess of the long diameter over the transverse. In a parietal of a brachycephalic, or of a dolichocephalic normal skull, this index has always been found to be greater, and has varied from 85 to 996 . In the scaphoid skull the excess of length makes up for the extreme narrowness, as the area of this half of the parietal amounted to 15,400 square millimetres. In order to determine whether this is a larger or smaller area than that of a parietal of an adult normal dolichocephalic or brachycephalic skull, Dr. Calori has made measurements, and found that the area of a parietal varies from 13,440 to 15,860 squares millimetres. By adding these amounts together, and dividing the sum by two, we obtain a medium of 14,650 square millimetres. It is clear that this medium is exceeded by the area of the half of the parietal region of the scaphoid skull, and that this latter may be regarded as rather large. Therefore Dr. Calori is induced to apply to this cranium the epithet parietal, an epithet which seems to be applicable to all the other examples described by the authors he quotes.

In the middle line of the parietal region, corresponding to the position of the sagittal suture, there rises an angular longitudinal process, or ridge, which extends down the frontal bone, and calls to mind the vertebral keel in the embryo. This process in the posterior fourth of the suture mentioned bifurcates, as a slight ridge descends the lambdoid suture, and terminates at the upper half of the occipital lambda. In the parietal portion of this ridge there is some appearance of a suture now effaced, an appearance which has led the author to consider that the sagittal suture must have closed there at last. This suture is now open only anteriorly; the open portion is somewhat more than a fourth of its length, and its aspect is in part slightly denticulated, in part as harmonia, these two varieties of suture alternating; whence it is manifest that the said portion of the sagittal suture would have become less if the boy had lived. In cases, certainly not rare, of precocious synostosis of the sagittal suture,

* Op. cit., Plate $x$. 
the author says he has often found the before-mentioned anterior portion still open.

In the middle of the parietal region, corresponding to the middle third of the longitudinal ridge, there is a slight boss, in which posteriorly the fine foramina parietalia are perceived. This boss is, moreover, full of vascular foramina, which run into vascular grooves, that spread in the form of rays upon the parietal planes. This disposition resembles a centre of ossification, and as such it has been regarded by Minchin and by Von Baer, who speak of it as single and common to the two halves of the region in question, so that, according to their opinion, there would be only one parietal in scaphocephalia, like a single frontal in cyclopia, whence would arise the cause of this deformation.

From the sides of the longitudinal process, or ridge, there extend two parietal planes, slightly convex, which from the first descend in the manner of a roof with two slopes. These planes, measured transversely, are a little more than two centimetres across, when they suddenly bend and descend to the temporal regions. There are no parietal bosses, and the contours of the semicircular lines are with difficulty perceived. Two similar planes to these descend at the sides of this process to above the much elevated frontal boss. The occipital region is most remarkable for its great prominence, and for the strong anterior curve of the lambdoidal angle, placed not exactly in the medium line, but slightly to the left, which angle much resembles the beak of a rapacious bird. It must not be omitted to be noted that the coronal and lambdoidal sutures are/both perfectly open.

We cannot follow the learned author throughout in his acute examination of the Biegnese scaphoid skull; and in the minute and accurate description which he devotes to it. $\mathrm{He}$ has not been able to ascertain from testimony whether Antonio suffered the same inability as the Pomeranian weaver, in not being able to look up to heaven, or raise his countenance to behold the stars. He is inclined to regard this want of power to have arisen, not from the great prominence of his occiput, but rather to some anchylosis of the cervical vertebræ, or to some defect of muscular power. In the Biegnese cranium the prominence of the forehead raises the facial angle to 850 . It presents two supernumerary teeth, which are seen in the face view. This view and that from behind do not present in outline one arc of a circle, but an arch of an acute form, as is usual in scaphoid skulls. The latter view does not present any occipital tubercle; the occipital crest and superior semicircular lines are scarcely indicated. The front view is notable in the facial ovoid for the 
nobility of the forehead, or the frontal portion of the frontal bone, notwithstanding the middle ridge in its upper half and the two planes which border it. The frontal portion being measured from the fronto-nasal suture to the centre of the coronal suture in a curved line, is one hundred and forty-two millimetres in length; and measured in the transverse curved line from one side to the other of the coronal suture on the level of the spheno-parietal suture, or the position of the anterior lateral fontanel, presents a breadth of one hundred and eighty-eight millimetres, a width which is very great.

In this part of his Letter, Professor Calori turns to the subject of the measurement of the area of the foramen magnum, and of its relation to the capacity of the skull, which is called the cerebro-spinal index. Professor Mantegazza had already, in 1870, in a memoir published in the "Rendicanti del Realo Istituto Lombardo di Scienze e Lettere," given an account of his own method of determining the area of the occipital foramen, which he effects by inserting in the foramen prisms of wood of known superficies, and filling up the voids with iron wires of a certain circumference.* Professor Calori prefers a different method of accomplishing the same purpose. He takes a cast of the foramen in plaster, makes an exact transverse section of this cast with a sharp instrument, and then applies it to a card or paper, which had been previously ruled with square millimetres. Lastly, with a pencil having a fine point, he draws a line upon the card, carefully running round the plaster cast. The area enclosed by this circular line is then easily read in square millimetres.

The area of the foramen magnum of this scaphoid skull, measured by Professor Calori's accurate method, amounts to nine hundred square millimetres. The capacity of the cranium itself, ascertained by filling it with sea-sand, a mode he has adopted for many years, is 1646 cubic centimetres. This shows a relation of the area to the capacity of eighteen to twenty-two. As Calori explains, he designates this relation, not the cephalospinal index (for the area is not the cubic capacity of the thecavertebralis), but simply the area of the foramen; and he considers that it would agree with this proportion of eighteen to twentytwo to apply to it the epithet, "trema occipito-craniale." $\mathrm{He}$ states his reasons besides for not receiving even this relation with too much confidence, or drawing reliable conclusions from it.

Professor Calori next presents a long table of measurements derived from the Biegnese scaphoid skull, of which we shall mention only two or three. The horizontal circumference is

* “Dell' Indice Cefalospinale nell' Uomo e nelle Scimmie Antropomorfe, e del Metodo per determinarlo." 
554 millimetres; greatest longitudinal diameter, 208 millimetres ; greatest transverse diameter, 136 millimetres; vertical diameter, 139 millimetres ; cephalic index, $\cdot 61$. In the skull of the Pomeranian weaver the horizontal circumference is 548 millimetres; greatest width, 122 millimetres; and cephalic index, $\cdot 55$.

Professor Calori has met with another instance of scaphocephalism in a man of Bologna, aged fifty-four years, of whom he gives a portrait in profile (Taf. V.). This man, he says, is an exception to the rule he had previously mentioned, that those having scaphoid skulls usually die in early life. Another case, which has just come to our knowledge, through the kindness of Mr. D. B. Balding, F.R.C.S.Eng., of Royston, equally proves that a more lengthened life may occur among those who manifest this extraordinary development. It is the case of an uneducated agricultural labourer, who was recently admitted into the Royston workhouse, in Hertfordshire. His scaphocephalism is strikingly marked, for he is commonly called "boat-head" in the vicinity, and his age is between fifty and sixty years. The Bolognese scaphocephalus suffers from time to time from headaches, and was formerly subject to accessions of religious mania. $\mathrm{He}$ is one of fourteen children, all the others being well-formed, and without any unnatural length of head. His scaphocephalism was observed at birth. By a careful examination of his head Professor Calori was enabled to ascertain that both the coronal and lambdoidal sutures are open, whilst the sagittal is effaced; and there exists the middle ridge running along the uniparietal described in the Biegnese example, the parietal bosses being equally absent.

After this very interesting narrative portion of his letter, Professor Calori turns to the speculative, or theoretical, which relates to the origin of scaphocephaly. Two opinions have been expressed upon this point; that of Minchin and Von Baer that the cause of the deformation lies in the ossification of the parietals from one single germ, which is developed in the situation of the sagittal suture, and that in reality there is but a single parietal. The other opinion derives the deformity from a previous synostosis of the parietals, or the ossification of the sagittal suture, allowing that each parietal had originally its own centre of ossification. Neither of these two views is quite satisfactory to Professor Calori. In the first, it is assumed that the two usual points of ossification corresponding to the parietal bosses are wanting, and that their defect is supplied by a central osseous point being developed in the situation of the absent suture, and performing its office by irradiating from the centre to the periphery of the region. But this is quite other than proved, 
for the scaphoid skull of Antonio contradicts such a view, by the manifestation of the duplicity of the parietals in the persistence of more than the anterior fourth of the sagittal suture, and in the aspect of its posterior fourth, indicating that the suture has not long disappeared. In this cranium, as in so many other examples, the parietals are narrow, and suddenly descend from the median line of the vertex to the sides, which will bring their centres of ossification up higher, and make them approach more and more to this central line, a circumstance which gives to these centres the faculty of joining into one, whence the appearance of a single osseous germ common to the two parietals in the centre of these bones. In this position, and particularly in the place in which we see in our scaphoid skull the slight parietal boss of the vertex, there is a great vascularity perceived in many minute vessels which traverse it from the interior to the exterior, or from the exterior to the interior, and which have left there a multitude of small branches and capillary grooves, which anastomose with those that follow the osseous rays running towards the place of the obliterated suture from the two parietal centres of ossification. Which circumstances and the above-mentioned approach of these centres must demonstrate much vigorous and increased ossifying activity there, and therefore display the precocity of the synostosis. The ridge is of itself a matrix of ossification, and able to engender distinct bones, or Wormians. It might be thought that the germs of these fortuitous bones, in the defect of normal osseous germs of the parietals, would lose the quality of simple osseous islands, and becoming more and more active, and extending to the entire parietal region with their radiations, would supersede the ultimate germs mentioned. But as, in our scaphoid cranium, so large a portion of the sagittal suture is still open, ought not this suture to have been all pervious behind? "There is not, then, in my opinion," says the author, "in scaphocephalic anomalies a native singleness of parts which ought normally to have been double, but a precocious union of parts which ought to be separated. This is in accordance with the opinion of Welcker, who denies that the origin of scaphocephalism lies in a single centre of ossification for the two parietals, an opinion to which you also are inclined. The scaphoid cranium I have described here is one of the proofs of this, and the opinion is in my case already demonstrated, so as to leave no doubt in the mind of any one that the parietals in scaphocephali are developed by two osseous germs, according to the laws which govern their ossification normally. But, if the production of scaphocephalism is not from one single centre of ossification for the two parietals, much less is it from precocious synostosis of the sagittal suture; 
and you have already first demonstrated this, producing twentyseven crania of your Collection all devoid of that suture, but which nevertheless, save four of them, do not present the deformity of scaphocephalism.* Whence it is reasonably established that this deformity is not an ordinary, but a rare and exceptional effect of the precocious synostosis of the suture in question. I myself possess crania of youths synostotic in the sagittal suture, none of which are scaphocephalic; part of them are dolichocephalic, part brachycephalic; which shows that such synostosis is not a character of dolichocephaly, as it appears to be in the methodic distribution of Virchow and of Lucaet of the deformities of the skull, and is still less an occasion or cause of the same. The brachycephalic skull of a little boy of thirteen years, with a cephalic index of eighty, shows synostosis of the three posterior fourths of the sagittal suture, and on the right side of the mastoido-occipital, mastoido-parietal and parieto-occipital only in correspondence to the posterior inferior angle of the parietal, yet the cranium is neither irregular, pyriform, nor apiocephalic. You have much more truly said, that the cranial deformities named by Virchow and Lucae are not necessary and invariable consequences of this or that synostosis, to which they have assigned in each case the same deformity, and that it is not always the same synostoses which mark and occasion the same deformity. I may now add, that there may be deformity of the skull without any synostosis of the sutures.

"In my Collection, the greater number of the deformed crania are plagiocephali, in which there exists as an accompaniment and an occasion the precocious synostosis of one half of the coronal suture. But, among these plagiocephalic skulls, there is one of a girl of twelve years of age, brachycephalic, with a cephalic index of 87 , an idiot from birth, which cranium presents all the sutures, and none of them shows any approach to obliteration; so that it is an instance of plagiocephaly without its presumed cause. It may be added that this skull is little and round rather than otherwise, and might serve as an example of microcephalia and of trochocephalia. A cranium of a woman of almost perfect rotundity is preserved in the Museum of Pathological Anatomy of the University of Bologna, and has all the sutures pervious, although the woman to whom it belonged could not be very young, and was demented. I possess the skull of a woman of middle age, dolichocephalic, with a cephalic index of $\cdot 77$, and pachycephalic, which has no synostosis of any suture; and I have seen the cranium of a leptocephalic old woman, which not only has no synostosis of any suture, but in

* "On Synostotic Crania", p. 30.

$\uparrow$ Ibid., pp. 7, 8. 
which, after maceration, the sutures were no longer sufficient to hold the bones of the vault together, there being diastases, as in the crania of little children. These facts lead me to conclude that synostoses, when they accompany deformity of the skull, are not the true causes of it, or so certainly the causes. Deformities may exist without synostoses, and may, according to this view, be occasioned partly by mechanical actions, partly by diseases, especially of the bones of the cranium and of the brain, and partly from the mode in which the brain grows and is developed. In speaking of mechanical actions, I do not mean the effects of those artifices which were and are still adopted by certain people to fashion at their pleasure the heads of newborn children, but those which sometimes take place from the influence of incommodious positions of the head of the foetus in utero; from compressions which the mother may exercise upon it for a long time by the pursuit of some toilsome trade; by the use of cinctures, or too tight and hard stays ; by habitually carrying weights upon her head, whence the abdominal muscles contract strongly, especially when the bearer makes a false step; from the influence of parturition, whether difficult, artificial, or constrained; from the supine or lateral position of infants in swaddling-clothes excessively protracted; from the falls of babies or young children upon the head; and from other such influences operating in a similar manner, which everyone may easily imagine. No doubt these mechanical actions, or causes, are more or less adapted and influential in deforming the head of the foetus, of the newly-born, of the infant, of the child, in such a manner as they are most apt and influential in producing deformity in other parts of the body. In like manner, rickets, osteomalacia, syphilis, hydrocephalus, eruption as well general as partial of the hairy scalp, accompanied with a slight degree of phlogosis, or with hyperæmia of the tissues beneath, and especially of the pericranium, and also of the dura mater (by which hyperæmia the deposition of earthy salts is more abundant, and the sutures also may disappear), are all to be taken into account among the very efficient causes producing deformity of the skull. And as to osteomalacia, I nust not omit to cite the astonishing examples of skulls deformed by it, which are collected and preserved in the Museum of Pathological Anatomy by our excellent colleague Professor Cæsar Taruffi, who will be glad to show you them, if you will favour him on another of your visits to Bologna. But, of all these causes, it appears to me that the most powerful is the mode of development and increase of the brain. It is a certain thing that the cranium takes the form of this most noble organ, which grows specially according to its longitudinal diameter, or according to the 
transverse or vertical; or else it is arrested in its development and increase much before its natural term; or it is developed, whether longitudinally or transversely, more in one than in the other hemisphere; or it does not grow duly in height, and deviates more and more without conforming to its normal shape; whence there will be sometimes long crania, broad or short crania, pyramidal or sugar-loaf crania, small crania, oblique or plagiocephalous, platycephali, etc. These are not merely suppositions, but, in fact, the known births of round heads, elliptical, acuminated, flat, distorted, etc. ; and some of the examples of deformity of the cranium related above, convince us of the truth of these views. It would not, probably, be wandering far from the truth to maintain that no small part of the deformity of the cranium may be produced by the mode in which the brain is developed and grows, and that on the cranium becoming deformed from such cause there might successively intervene synostoses, which often accompany the, deformities ; it may be because given bones find themselves in more intimate contact by their edges, it may be because in that place the brain having ceased to grow, there is a greater afflux of nutritious humours, a greater deposition of earthy salts. Similar, it appears to me, have been the proceedings which have produced the deformity of the skull in the scaphocephalic Biegnese, in the Bolognese, and in others also. Excessive congenital elongation of the brain, excessive narrowness, likewise congenital, of the same organ, chiefly superiorly, a form not low upon the whole, but strongly folded towards the arch; such suits itself to the embryo or to the fœetus in its first period; consecutive synostosis of the sagittal suture in the manner which I have above pointed out, should constitute the proceeding followed by nature in producing scaphocephaly. Which proceeding may take place whenever it may be believed to have been helped by any of the other of the above-mentioned causes, and especially the mechanical ones, as a slight and often-repeated lateral compression, upon the head of the fotus, made by the mother. This would not be contradicted if the compression should always be estimated as a concurrent cause, being such an occasion not in and by itself available to engender scaphocephaly, as the well ascertained cases prove in which the compression exercised its power, and which have always retained as the first mover the mode or the direction of the development and increase of the brain. I insist upon this condition, which I look upon as primary and indispensable to the production of the deformity, because the cranium, soft and most pliant in the embryo and the foetus, would not have in itself power to work or effect it, and it is subordinate to the brain. A condition which might be suggested, and in the same 
way confirmed in its genetic importance, is the fact that in the smallest embryos the brain is long, narrow, and much folded, and consequently so is the cranium itself, which may be especially perceived in the posterior and superior part of its vault, somewhat like the keeling of the dorsal spine; a form which, not expanding at the proper time in a normal manner and measure, especially at the superior posterior region of the cerebral hemispheres, may thus perpetuate itself and produce scaphocephaly. I perceive clearly that this mode of its genesis will probably not appear to be well contrived; but not valuing the suppositions of one single and common centre of ossification common to the two parietals, nor that of the precocious synostosis of the sagittal suture, I have not known how to find a better."

These are mainly fresh views of the causes of scaphocephalism, which we have thought it desirable to state as nearly as may be in their author's own words. He adds that, if they be erroneous, he shall be grateful to have them corrected.

\section{On Certain Points concerning the ORigin and Relations of the Basque Race. By the Rev. W. Webster.}

DURING the last two years, a phrase has cropped up in treating of English history, not, indeed, unknown before, but hardly seriously maintained-viz., "Our Iberian forefathers," meaning by Iberian a race of which the Basques are the presumed modern representatives. This phrase, I think, needs careful examination. The three chief classes of evidence for the descent of peoples are-1, Historical; 2, Philological; 3, Anthropological.

The Iberian descent of the modern English, Irish, and Welsh from the Basques is said to be through the Kelts, and through that particular section of them which has been denominated the Black Kelts. I am not aware that the least historical or other evidence has been brought forward that this division of Kelts into black and white marks a real difference of race. But the theory has been extensively adopted, and has found its latest expression in the assertion of an anonymous writer in the Guardian newspaper, that "the Bretons and Basques are the same people."

The problem we have to examine, then, is whether the black Kelts - whether of England, Ireland, Wales, or Brittany - are identical with, or descended from, the Basques. Some colour may be given to the theory, in the minds of those who can accept it, by the dictum of Pliny, that Aquitania was formerly called Aremorica- "Aquitania, Aremorica antea dicta." Still more support may be gained from the words of Tacitus about the Silures, 